\title{
Commentary: Prolactin Alters Blood Pressure by Modulating the Activity of Endothelial Nitric Oxide Synthase
}

\author{
Jakob Triebel ${ }^{1 *}$, Carmen Clapp ${ }^{2}$, Gonzalo Martínez de la Escalera ${ }^{2}$ and Thomas Bertsch ${ }^{1}$ \\ ${ }^{1}$ Institute for Clinical Chemistry, Laboratory Medicine and Transfusion Medicine, Nuremberg General Hospital, Paracelsus \\ Medical University, Nuremberg, Germany, ${ }^{2}$ Instituto de Neurobiología, Campus UNAM-Juriquilla, Universidad Nacional \\ Autónoma de México (UNAM), Querétaro, México
}

Keywords: prolactin, vasoinhibins, 16K PRL, blood pressure, prolactin/vasoinhibin axis

\section{A commentary on}

Prolactin Alters Blood Pressure by Modulating the Activity of Endothelial Nitric Oxide Synthase by Chang AS, Grant R, Tomita H, Kim HS, Smithies O, Kakoki M. Proc Natl Acad Sci U S A (2016) 113(44):12538-43. doi:10.1073/pnas.1615051113

Chang et al. report the modulation of blood pressure by prolactin and one of its cleaved products, a $16 \mathrm{kDa}$ vasoinhibin isoform also referred as $16 \mathrm{kDa}$ prolactin (1). They use transgenic mice producing prolactin in the liver and show that overexpression of the prolactin transgene leads to higher circulating levels of the vasoinhibin, which upregulates blood pressure by modulating the activity of endothelial nitric oxide synthase (eNOS). The high hepatic prolactin production leads to a surge in plasma prolactin levels. The circulating vasoinhibin might also originate in the liver, as the generation of the $16 \mathrm{kDa}$ vasoinhibin isoform has been documented in rodent liver (2). Alternatively, the vasoinhibin could have been generated at a site other than the liver, as has been observed in various other organs and tissues such as the pituitary gland, heart, kidney, and vascular endothelium [reviewed in Ref. (3)]. Analysis of vasoinhibins in tissue homogenates and blood samples drawn from multiple veins may help answer this question.

The vasoinhibin isoform in the plasma of transgenic mice overproducing hepatic prolactin was characterized by Western blot analysis. The apparent molecular mass of $16 \mathrm{kDa}$ was assigned presumably based on a molecular mass marker co-migrating in the SDS-PAGE. Prolactin cleaved by cathepsin D between tyrosine 147 and proline 148 would have a theoretical mass of $16.8 \mathrm{kDa}$ (4). However, due to a lack of precision in the molecular mass determination, the band observed could also correspond to the $17.2 \mathrm{kDa}$ cathepsin D-cleaved product (cleavage site: tryptophan150serine151) (4) or the matrix metalloproteinase (MMP)-cleaved vasoinhibin isoform (cleavage site: serine155-leucine156) (5), or a mixture of both. This is relevant, as the composition of vasoinhibin isoforms varies among reproductive hypertensive diseases $(3,6)$. Nevertheless, the result shown in the current analysis is informative, as it indicates little or no generation of other vasoinhibin isoforms by cathepsin D or MMP $(11,12.5,14.1,15$, and $17.7 \mathrm{kDa})$ in this animal model. The question of whether the $16 \mathrm{kDa}$ vasoinhibin is a greater proportion of the total prolactin or reflects higher total prolactin could be answered by evaluating the optical density of prolactin and vasoinhibin values, provided the image is scaled to an intensity at which the prolactin signal is not oversaturated and the vasoinhibin signal is still visible.

The data suggesting that hyperprolactinemia results in higher circulating vasoinhibin levels which, in turn, induce plasminogen activator inhibitor-1 expression, lower eNOS phosphorylation/ activation, and reduce nitric oxide production are novel, and they complement information regarding endocrine circuits in the prolactin/vasoinhibin axis and their relevance for cardiovascular function (3). Emphasis should be placed on evaluating circulating vasoinhibins when testing pregnant women 
for abnormally high prolactin levels. This is because of the wide range (35-600 $\mathrm{ng} / \mathrm{ml}$ ) of hyperprolactinemia values occurring in pregnancy (7) and the unclear correlation between circulating prolactin and pre-eclampsia (6).

\section{REFERENCES}

1. Chang AS, Grant R, Tomita H, Kim HS, Smithies O, Kakoki M. Prolactin alters blood pressure by modulating the activity of endothelial nitric oxide synthase. Proc Natl Acad Sci U S A (2016) 113(44):12538-43. doi:10.1073/ pnas. 1615051113

2. Clapp C. Analysis of the proteolytic cleavage of prolactin by the mammary gland and liver of the rat: characterization of the cleaved and $16 \mathrm{~K}$ forms. Endocrinology (1987) 121(6):2055-64. doi:10.1210/endo-121-6-2055

3. Triebel J, Bertsch T, Bollheimer C, Rios-Barrera D, Pearce CF, Hufner M, et al. Principles of the prolactin/vasoinhibin axis. Am J Physiol Regul Integr Comp Physiol (2015) 309(10):R1193-203. doi:10.1152/ajpregu.00256.2015

4. Piwnica D, Touraine P, Struman I, Tabruyn S, Bolbach G, Clapp C, et al. Cathepsin D processes human prolactin into multiple 16K-like N-terminal fragments: study of their antiangiogenic properties and physiological relevance. Mol Endocrinol (2004) 18(10):2522-42. doi:10.1210/me.2004-0200

5. Macotela Y, Aguilar MB, Guzman-Morales J, Rivera JC, Zermeno C, LopezBarrera F, et al. Matrix metalloproteases from chondrocytes generate an antiangiogenic $16 \mathrm{kDa}$ prolactin. J Cell Sci (2006) 119(Pt 9):1790-800. doi:10.1242/ jcs.02887

\section{AUTHOR CONTRIBUTIONS}

JT wrote the manuscript. CC, GE, and $\mathrm{TB}$ revised the manuscript.

6. Gonzalez C, Parra A, Ramirez-Peredo J, Garcia C, Rivera JC, Macotela Y, et al. Elevated vasoinhibins may contribute to endothelial cell dysfunction and low birth weight in preeclampsia. Lab Invest (2007) 87(10):1009-17. doi:10.1038/ labinvest. 3700662

7. Tyson JE, Hwang P, Guyda H, Friesen HG. Studies of prolactin secretion in human pregnancy. Am J Obstet Gynecol (1972) 113(1):14-20. doi:10.1016/00029378(72)90446-2

Conflict of Interest Statement: The authors declare that the research was conducted in the absence of any commercial or financial relationships that could be construed as a potential conflict of interest.

Copyright () 2017 Triebel, Clapp, Martínez de la Escalera and Bertsch. This is an open-access article distributed under the terms of the Creative Commons Attribution License (CC BY). The use, distribution or reproduction in other forums is permitted, provided the original author(s) or licensor are credited and that the original publication in this journal is cited, in accordance with accepted academic practice. No use, distribution or reproduction is permitted which does not comply with these terms. 